1 Elson S Floyd College of Medicine, Washington State University, USA

2 College of Nursing and Health Sciences, University of Massachusetts, Dartmouth, USA

3 Escuela de Enfermeria, Universidad Catolica Santo Toribio de Mogrovejo Peru

Correspondence to: P Butterfield pbutter@wsu.edu

Cite this as: $B M J \$\{y e a r\} ; 373: n 1049$ http://dx.doi.org/10.1136/bmj.n1049 Published

THE FUTURE OF NURSING

\title{
Nursing's pivotal role in global climate action
}

Nurses moved early and eagerly to advocate action to resist climate change and are well positioned to achieve much more. Patricia Butterfield, Jeanne Leffers, and Maribel Díaz Vásquez urge nurses to act boldly within and across professional boundaries

\section{Patricia Butterfield, ${ }^{1}$ Jeanne Leffers, ${ }^{2}$ Maribel Díaz Vásquez ${ }^{3}$}

Climate change threatens the very foundations of human health and existence. ${ }^{1}$ The planet has warmed more than $1.2^{\circ} \mathrm{C}$ compared with preindustrial levels, precipitating profound and rapidly worsening health effects on every continent. ${ }^{2}$ Despite overwhelming evidence, however, the global response to climate change has been mired in political intransigence and bureaucracy. Health professionals have been increasingly looked to for leadership, and their sustained commitment is dealing with critical gaps in climate science, policy, and advocacy. ${ }^{2}$

The nursing profession came to the climate debate early (box 1) and is well positioned to expand its role. Nurses have three essential assets. Firstly, they comprise about $60 \%$ of health professionals (medical doctors, nurses, midwives, dentists, and pharmacists) worldwide, working in many clinical and public health sectors. ${ }^{3}$ Their collective potential to change the trajectory of climate action is unparalleled.

Box 1: Past as prologue-milestones in dealing with climate action and environmental health

- 1859: All roads lead to Florence-Nursing's leadership originated with Florence Nightingale's 1859 treatise on ventilation and light. Her progressive and subversive work made it clear that all health is environmental health; all life depends on the earth's primal assets

- 1986: "The vastness and urgency"-The International Council of Nurses called on nurses to tackle "the vastness and urgency" of environmental issues. In a bold and forward thinking declaration, the council told nurses that they shared the responsibility of protecting the world. Subsequent position statements were released in 2008 and 2018

- 1995: Nursing and environment on the national stage-The US based Institute of Medicine released Nursing, Health, and the Environment

- 1996: Right before their eyes-Nurses began to understand that healthcare itself perpetuated climate change. Discarded tubing and vials were a daily reminder of what was wrong. Cofounded in 1996 by a nurse and an environmental health activist, Health Care Without Harm, and other groups worked to rebrand climate change from a narrowly defined ecological concern to one with consequences for public health

- 2008: Building organizational infrastructure-Both nursing and interdisciplinary organizations were founded-for example, the Alliance of Nurses for Healthy Environments (2008), the Canadian Association of Nurses for the Environment (2009), and United Kingdom Health Alliance on Climate Change (2016)

- 2010-present: Transforming the curriculum-Educators began to include climate change in curricular blueprints, in which it had been noticeably absent. Materials, initially descriptive, soon became focused on action and situation; challenges included overcrowded curricula and lack of faculty capacity and expertise. Student outcomes showed that students were receptive to climate change education

- 2014-present: At the table-Nurses collaborated with other health professionals to create national and international policy. Early successes in this area included substantive recommendations from the White House (2016). Nursing leadership has been instrumental in advancing the work of the Global Consortium on Climate and Health Education and the Climate and Health Alliance. Both the International Council of Nurses and the American Academy of Nursing have led throughout the years

Secondly, nurses are trusted. The US based Gallup poll, in which nurses were ranked as the most trusted profession for the past 19 years, is often cited, but is far from unique. ${ }^{4}$ The UK focused Ipsos Veracity Index ${ }^{5}$ shows that nurses ranked number 1 among 30 professional groups. Doctors, engineers, and teachers also fared well, but nurses are generally perceived as being accessible and responsive to the needs of others. ${ }^{6}$ Nurse are often the first health provider that people meet when they are seeking care. ${ }^{3}$ Nursing has immense potential to create and disseminate messages about the climate that are acceptable to those who are doubtful about climate change.

Thirdly, nurses are close to the people most vulnerable to climate change. Many nurses work for people who are underserved or marginalized, or both. Nurse staffing numbers have been associated with reduced mortality from climate sensitive diseases such as malaria, dengue fever, and schistosomiasis. ${ }^{3}$ In a recent analysis of mortality data from 53 sub-Saharan African countries, the staffing levels of nurses and midwives were found to be the strongest predictor of lower covid-19 deaths. ${ }^{7}$

In unstable places, the presence of nurses makes a difference. Imagine the possibilities if the scope of nursing worldwide was expanded to include actions dealing with climate change. 


\section{An unprecedented challenge}

Through grit and mutual support, nursing has built a solid body of work operationalizing climate action (box 1). Unfortunately, we know these efforts are not enough. As the Lancet Countdown starkly noted, "An unprecedented challenge demands an unprecedented response, and it will take the work of the 7.5 billion people currently alive to ensure that the health of a child born today is not defined by a changing climate." ${ }^{1}$

The current pandemic provides further validation that "creating a healthier, fairer, and greener world" will be needed to resuscitate economies hit by the effects of covid-19. ${ }^{8}$ The International Council of Nurses has noted that covid-19 has forced the world to pause and take stock of opportunities to benefit the planet, stating "It may be the only chance we have for anything positive to come out of the covid-19 pandemic, and to let this opportunity slip by would be unforgivable." In this context, we offer five recommendations.

\section{Leapfrog nurses into leadership roles}

Accelerate change by leapfrogging nurses into leadership roles. Several initiatives have focused on moving nurses into executive level leadership roles. ${ }^{10}$ These programs assume that healthcare will improve if nurses are at the table, rather than in roles remote from power.

Several initiatives of the global Nursing Now campaign, championed by the UK charity the Burdett Trust for Nursing, have focused on gender disparities, noting that although women comprise $70 \%$ of the healthcare workforce, they represent only $25 \%$ of leadership roles. ${ }^{10}$ Due to complete its work this year, Nursing Now shows what will be needed to increase nurses' leadership capacity. Realizing the potential of nurses as climate action leaders will require thorough coaching in project design. Leadership programs for climate action are needed for nurses worldwide; such efforts should allow protégés and mentors to work together.

The International Council of Nurses, with its familiarity with the nursing workforce and environmental health, is well equipped to champion tactical goals in this area. Additionally, for far too long work on climate change carried out by nurses in hospitals and academia has gone uncompensated. The longstanding practice of expecting nurses to "help" with climate projects-that is, to donate their time with inadequate recognition, needs to end.

\section{Give nurses the right skills}

Give nurses and students the skills they need to create the future. Nurses in clinical practice have great potential to enact climate protective actions; providing resources for them should be a top priority for the profession. Practicing nurses understand the organizational lay of the land; they often have new ideas for projects and have coped with organizational barriers. To be successful they will need basic training in environmental health problems, a modest project budget, and ongoing professional mentoring.

Fortunately, for professional development the news is good. New resources are being released daily. Information is available from sources such as the Climate Change and Health program (at the MGH Institute of Health Professions), the Global Consortium on Climate and Health Education, and Project ECHO's Climate and Health series. These groups provide basic resources to others, including webinars, online courses, syllabi, and case studies (box 2). Of note is the Nigeria based GalesActGreen initiative, which focuses on building a network of climate literate nurses to serve as agents for change throughout Africa. These recent advancements are cause for celebration.

\section{Box 2: Nursing and health climate organizations and initiatives}

- Global Alliance of Nurses for Healthy Environments (www.envirn.org)

- Canadian Association of Nurses for the Environment/Association d'infirmières et infirmiers pour l'environnement (http://www.cnheiise.ca/)

- Center for Climate Change, Climate Justice, and Health (https://www.mghihp.edu/climate)

- Climate and Health Alliance Australia (https://www.caha.org.au/)

- Climate Change and Health Curriculum (https://globalhealthcenter.umn.edu/climate-change-and-health-curriculum)

- Climate Change and Human Health ECHO (https://hsc.unm.edu/echo/institute-programs/climate-change/)

- ECOSERV Lambayeque Peru (https://www.ecoservperu.com)

- GalesActGreen Nigeria (@GalesAct: https://twitter.com/GalesAct? $\mathrm{s}=08$ )

- Global Climate and Health Alliance (https://climateandhealthalliance.org/about/)

- Global Consortium on Climate and Health Education (https://www.publichealth.columbia.edu/research/global-consortiumclimate-and-health-education)

- International Council of Nurses (https://www.icn.ch/nursing-policy/position-statements)

- International Council of Nurses collaboration with WHO (https://climateandhealthalliance.org/working-group/)

- Millennial Nurses Network, Santiago, Chile (https://portal.alemana.cl/wps/wcm/connect/ingles/home/news/clinica-alemanapresents-its-fourth-sustainability-report)

- National Student Nurses Association (https://www.nsna.org/population-and-global-health-committee.html)

- Nurses Climate Challenge (https://nursesclimatechallenge.org)

- Nurses Drawdown (https://www.nursesdrawdown.org/)

- NurSuS, UK, Europe (http://nursus.eu/about-us/)

- Universidad Cooperativa de Colombia (https://www.ucc.edu.co/Paginas/inicio.aspx)

- UK Health Alliance on Climate Change (http://www.ukhealthalliance.org)

- UN Climate Justice in Sustainable Development Goals (https://www.un.org/sustainabledevelopment/blog/2019/05/climatejustice/)

The development of curricular resources, guides, and tools has been a strong suit for nursing. Most developments have been aimed at normalizing climate actions within nursing practice. Among existing resources, the NurSuS Toolkit, which focuses on sustainability, is most easily scalable globally. ${ }^{11}$ Environmental sustainability and stewardship need to be taught so that nurses and students not only understand but also have the ability to initiate change. Two other cross-cutting topics are imperative: risk communication and public health systems thinking; both receive inadequate attention in undergraduate and graduate programs.

We recommend a strong curricular pivot towards risk communication; many nurses receive too much content (often antiquated) on therapeutic communication. In contrast, risk communication focuses on applying science based information to health events in order to promote informed decision making. Messages from nurses about climate action are stronger when they are framed in risk communication vernacular. 
As for risk communication, nurses' skills in dealing with public health systems need to be improved and focus on action rather than description. Recent pedagogical work, conducted under the auspices of planetary health and sustainable development, emphasizes the importance of interdependent ecosystems and global inclusivity; both are fundamental to an understanding of public health systems. ${ }^{12-14}$ Making these proposed changes standard in nursing curriculums will not only increase nursing's leadership capacity, but will also make nursing boards and licensing councils take notice and reconsider the importance of knowledge of fundamental climate change as a prerequisite for licensure.

\section{Promote activism and advocacy}

Rekindle activism, advocacy, and relentless truth telling. In August 2018 Greta Thunberg began protesting in front of the Swedish parliament, holding a sign that read "Skolstrejk för Klimatet" (school strike for climate). The pace at which she amplified the global response to climate change was exceptional. Her solemn indignation is emblematic of a new generation of environmental activists, ${ }^{15}$ who believe that climate deniers should not be placated; antiscience groups should be exposed. Nurses in the UK and elsewhere have found resonance with this approach to activism, urging their employers to adopt ambitious policies to tackle environmental sustainability. ${ }^{16}$ Activism can take many forms, including protests, petitions, and political engagement (including running for office). Nursing should not be shy about using its voice for change.

Advocacy is fundamental to change in systems and structures. ${ }^{17-19}$ Alliances such as the UK Health Alliance on Climate Change and the Global Climate and Health Alliance typify strong interprofessional efforts focused on policy advancement.

In addition to taking on interprofessional work, nurses have also recognized that speaking the truth also means critically examining their own healthcare practices. Acknowledging responsibility for climate change has led to the development of initiatives such as the Nurses Climate Challenge (focused on climate education) and the Nurses Drawdown (focused specifically on greenhouse gas emission); such efforts represent effective conduits for collective action. ${ }^{15} 2021$

\section{Think global}

Assure a global viewpoint by removing Western bias from nursing's agenda for climate action.

The phrase "while we are in the same storm, we are not in the same boat" serves as a poignant framing device for both covid-19 and climate change. For example we know that small island developing states are disproportionally vulnerable to the direct and indirect effects of climate change..$^{22}$ To date, however, the voices of nurses in highly affected communities have received far less attention than those from Western nations.

Nursing should strengthen its commitment to indigenous practices, and ancestral knowledge that is climate protective. Nursing's climate action stance can change from that of a white and wealthy world to one that is more inclusive.

The wisdom of nurses in low and middle income countries needs to be incorporated into the global climate discourse; their work ranges from subjects as diverse as the response to megafires in the Amazon to the promotion of low emission cooking stoves that safeguard respiratory health. ${ }^{23} 24$ The United Nations sustainable development agenda (inclusive of 17 sustainable development goals) exemplifies a more inclusive approach to change. ${ }^{13} \mathrm{Key}$ stakeholders, including the International Council of Nurses, are prioritizing the climate action needs of high risk countries. ${ }^{25}$ Nursing organizations are beginning to reflect regional (eg, Pan American) strengths and international viewpoints. ${ }^{26}$

\section{Climate change is a moral problem}

Make equity, justice, and, yes, morality, front and centre. The convergence of the climate action and health equity agendas has been accelerated by the covid-19 pandemic, reflecting the all too obvious truth that while the rich have the means to escape many forms of tragedy, the poor are stuck.

Astute leaders are blaming corporate greed and governmental corruption as causes of climate change. ${ }^{27}$ Theologians have been effective in reminding us that climate change fundamentally represents theft of the world's assets from future generations. Pope Francis's 2015 encyclical notes that many of those who "have more resources and economic or political power seem to concentrate mainly in masking the problems." 28

Nurses can be more effective bearers of the moral story of climate change. We have a legacy of protecting human dignity. The public is comfortable with nurses talking about right and wrong. We should not hesitate to discuss the rights of future generations, vulnerable groups, and indigenous peoples. We should form partnerships with colleagues in public health, medicine, and behavioural health, accept challenges, and seek responsibility.

\section{What did you do?}

"The future will ask, what did you do?" is a succinct and startling provocation that reminds us what is at stake for us and our children. ${ }^{29}$ Much needs to be done, and quickly (box 3). By building on what we have done, and more importantly, who we are, nursing has both the skills and the mindset to meet the moment.

\section{Box 3: How to achieve the recommendations}

\section{Accelerate change by leapfrogging nurses into leadership roles}

- Employ recent international initiatives that can move nurses into executive level leadership roles

- Foster representation of nurses on international and national boards, congresses, governmental panels, and delegations as high level decision makers

- Build partnerships among nursing organizations globally to strengthen the power of the profession

- Amplify leadership in sustainable healthcare initiatives in the workplace and community

- Pay for nurses' climate change work

Give nurses and nursing students the skills they need to create the future

- Mandate that the national nursing education curriculum and accrediting bodies include climate change content and action plans into graduate and professional development education

- Clarify the effects of climate change on health in the clinical practice requirements of boards of registration and national licensing councils

- Integrate sustainability literacy and action into pre-licensure and professional nursing education using tools such as the NurSuS toolkit

- Develop educational strategies for nursing advocacy skills that include risk communication and systems level approaches to problem solving for climate change

- Integrate planetary health, social determinants, health equity and lifespan, occupational and location specific vulnerabilities into nursing climate change education

- Ensure that education reinforces the responsibility of nurses to educate individuals, families, and communities to deal with mitigation, adaptation, and resilience strategies 
- Disseminate models, programs, and strategies of collaborative educational initiatives such as the Global Consortium on Climate and Health Education

\section{Rekindle activism, advocacy, and relentless truth telling}

- Amplify the voice of nurses to reach healthcare professionals, patients, families, and communities

- Extend the effectiveness of nursing by speaking truth to power to mitigate the effect of climate change on health

- Influence others by showing personal commitment to sustainable living choices using strategies promoted by Nurses Drawdown.org

- Bolster organizations to develop national action plans for mitigation, adaptation, and resilience strategies

- Advocate increases in funding and support for nursing research to build evidence for climate change strategies that improve health

- Seek to communicate with national leadership to end subsidies or other support to monoculture systems that harm biodiversity

- Advocate enforcement of regulations of air and water quality standards that protect communities from harmful effects of climate change

Ensure a global lens by extinguishing Western biases in the climate action agenda of nursing

- Promote a stronger voice from nurses in low and middle income countries in the international climate action agenda

- Adopt the successful climate change strategies developed in low and middle income countries as models for countries across the globe

- Rescue and make visible the ancestral knowledge and practices in the face of climate change

- Deal with the effects experienced by those living in low and middle income countries, such as extreme heat, drought, extreme weather events, rise in sea level, wild fires, and indoor cooking stoves, to improve health

- Extend the Nurses Climate Challenge to reach nurses in countries across the globe

Put equity, justice, and morality front and centre

- Call for health equity agendas to be central to climate actions

- Aim to achieve the sustainable development goals for all nations

- Value ecosystems to protect biodiversity

- Endorse an intercultural approach in indigenous areas to guarantee the right to health and a healthy environment

- Respond to the call of Laudato Si' to recognize the role of climate change in the lives of all people on earth, with disproportionate effect on the poor

- Expose corporate greed and governmental corruption as primary causes of climate change

- Advocate healthy communities to assure active transportation, green energy, and healthy, sustainable food options for all

Competing interests: We have read and understood BMJ policy on declaration of interests and have no relevant interests to declare.

Provenance and peer review: Commissioned; externally peer reviewed.

This article is part of a series commissioned by The BMJ for the World Innovation Summit for Health (WISH). The BMJ peer reviewed, edited, and made the decision to publish. The authors received no payment. The series, including open access fees, is funded by WISH, which is an initiative of the Qatar Foundation.

We thank the following nurses who provided input for this analysis: Laura Anderko, Cara Cook, M Ignacia González Elias, Christianah Jegede, Ruth McDermott-Levy, Janet Richardson, Doriam Camacho Rodríguez, Barbara Sattler, Elizabeth Schenk, and Claudia Zuniga.

Watts N, Amann M, Arnell N, etal. The 2019 report of The Lancet Countdown on health and climate change: ensuring that the health of a child born today is not defined by a changing climate. Lancet 2019;394:1836-78. doi: 10.1016/S0140-6736(19)32596-6 pmid: 31733928
2 Watts N, Amann M, Arnell N, etal. The 2020 report of The Lancet Countdown on health and climate change: responding to converging crises. Lancet 2021;397:129-70. doi: 10.1016/S0140-6736(20)32290-X pmid: 33278353

3 World Health Organization. State of the world's nursing 2020: investing in education, jobs, and leadership. 2020. https://www.who.int/publications/i/item/9789240003279

4 Gallup. US ethics ratings rise for medical workers and teachers. Press release, 22 Dec 2020. https://news.gallup.com/poll/328136/ethics-ratings-rise-medical-workers-teachers.aspx

5 Ipsos MORI. Ipsos MORI veracity index 2020: Trust in professions survey. November 2020. https://www.ipsos.com/ipsos-mori/en-uk/ipsos-mori-veracity-index-2020-trust-in-professions

6 Krislov M. What we can all learn from nurses. Forbes. February 18th, 2020. https://www.forbes.com/sites/marvinkrislov/2020/02/18/what-we-can-all-learn-from-nurses/?sh=3a6f91f245ca

7 Okeahalam C, Williams V, Otwombe K. Factors associated with COVID-19 infections and mortality in Africa: a cross-sectional study using publicly available data. BMJ Open 2020;10:e042750. doi: 10.1136/bmjopen-2020-042750 pmid: 33177146

8 World Health Organization. Actionables for a healthy recovery from COVID-19. World Health Organization Newsroom, 23 Jul 2020. https://www.who.int/news-room/feature-stories/detail/ac tionables-for-a-healthy-recovery-from-covid-19

9 International Council of Nurses. Over 40 million health professionals urge G20 leaders to put public health at the core of Covid-19 recovery. Press release, 26 May 2020 https:/www.icn.ch/news/over-40-million-health-professionals-urge-g20-leaders-put-publichealth-core-covid-19-recovery

10 IntraHealth International. Investing in the power of nurse leadership: what will it take? 2019. https://www.intrahealth.org/sites/ihweb/files/attachment-files/investing-nurse-leadershipreport.pdf

11 NurSus. NurSusTOOLKIT Project Plymouth, UK. http://nursus.eu/

12 Potter T. Planetary health: the next frontier in nursing education. Creat Nurs 2019;25:201-7. doi: 10.1891/1078-4535.25.3.201 pmid: 31427415

13 Rosa WE, Kurth AE, Sullivan-Marx E, etal. Nursing and midwifery advocacy to lead the United Nations sustainable development agenda. Nurs Outlook 2019;67:628-41. doi: 10.1016/j.outlook.2019.06.013 pmid: 31420180

14 Leffers J, Levy RM, Nicholas PK, Sweeney CF. Mandate for the nursing profession to address climate change through nursing education. J Nurs Scholarsh 2017;49:679-87. doi: 10.1111/jnu.12331 pmid: 28806483

15 Nurses Climate Challenge. Health care without harm. 2021. https://nursesclimatechallenge.org/

16 Jones-Berry S. Nurse managers urged to promote environmental sustainability: The RCN is lobbying healthcare providers to adopt strategies on environmental sustainability. Nurs Manage 2019;26:8-11.

17 Leffers J, Butterfield P. Nurses play essential roles in reducing health problems due to climate change. Nurs Outlook 2018;66:210-3. doi: 10.1016/j.outlook.2018.02.008 pmid: 29599047

18 Chiu P. Advancing nursing policy advocacy knowledge: a theoretical exploration. ANS Adv Nurs Sci2021:44:3-15. doi: 10.1097/ANS.0000000000000339 pmid: 33181569

19 Cook C, Demorest SL, Schenk E. Nurses and climate action. Am J Nurs 2019;119:54-60. doi: 10.1097/01.NAJ.0000554551.46769.49 pmid: 30896494

20 Demorest S, Spengeman S, Schenk E, Cook C, Weston HL. The nurses climate challenge: a national campaign to engage 5,000 health professionals around climate change. Creat Nurs 2019;25:208-15. doi: 10.1891/1078-4535.25.3.208 pmid: 31427416

21 Nurses Drawdown. Nurses drawdown: A project of the Alliance of Nurses for Healthy Environments and Project Drawdown. 2021. https://www.nursesdrawdown.org/about/.

22 World Health Organization. Climate change and health in small island developing states. A WHO special initiative. Geneva; 2018. https://apps.who.int/iris/bitstream/handle/10665/279987/9789241514996-eng.pdf?sequence=1\&isAllowed=y

23 Barría P RM. Wildfires as a public health problem: a setting for nursing in disasters. Invest Educ Enferm 2019;37:e01. doi: 10.17533/udea.iee.v37n3e01 pmid: 31830399

24 Díaz-Vásquez MA, Díaz-Manchay RJ, León-Jiménez FE, Thompson LM, Troncoso K, Failoc-Rojas VE. Adoption and impact of improved cookstoves in Lambayeque, Peru, 2017. Glob Health Promot 2020;27:123-30. doi: 10.1177/1757975920945248 pmid: 32829693

25 Catton $\mathrm{H}$. Global challenges in health and health care for nurses and midwives everywhere. Int Nurs Rev 2020;67:4-6. doi: 10.1111/inr.12578 pmid: 32083728

26 Alliance of Nurses for Healthy Environments. Exemplars of nursing leadership on climate change Sigma \& ANHE webinar series: A global movement for health. 2020. https://envirn.org/calendar/sigma-anhe-webinar-series-a-global-movement-for-health-nursing-leadership-on-climatechange-3/

27 Krieger N. Climate crisis, health equity, and democratic governance: the need to act together. J Public Health Policy 2020;41:4-10. doi: 10.1057/s41271-019-00209-x pmid: 31965049

28 His Holiness Pope Francis. Encyclical letter Laudato Si' of the Holy Father Francis on care for our common home. 2015. http://www.vatican.va/content/francesco/en/encyclicals/documents/papafrancesco_20150524_enciclica-laudato-si.html

29 Cox KS, Butterfield P. Environmental health: the future will ask, "what did you do?" Nurs Outlook 2018;66:526-7. doi: 10.1016/j.outlook.2018.10.002 pmid: 30502885

This is an Open Access article distributed in accordance with the Creative Commons Attribution Non Commercial (CC BY-NC 4.0) license, which permits others to distribute, remix, adapt, build upon this work non-commercially, and license their derivative works on different terms, provided the original 
work is properly cited and the use is non-commercial. See: http://creativecommons.org/licenses/bync/4.0/.

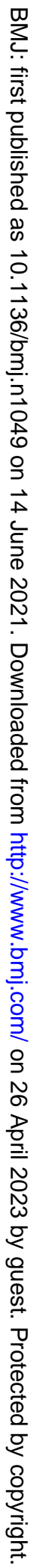

